\title{
Professor de canto, preparador vocal, fonoaudiólogo, otorrinolaringologista: quais os limites e as interseções da relação entre os membros da equipe de atendimento ao cantor com base na nova pedagogia vocal?
}

\author{
Danielle Dias Lima \\ Mestranda em Música pela UFRJ. \\ ORCID: https://orcid.org/0000-0001-7061-7813 \\ E-mail: danidias.lima@gmail.com \\ João Miguel Bellard Freire \\ Professor Adjunto (Escola de Música/ UFRJ) \\ Doutor em Música (UNIRIO) \\ Coordenador da Linha de Pesquisa em Educação musical do PPGM, UFRJ \\ ORCID: https://orcid.org/0000-0001-9559-5243 \\ E-mail: jmbfreire@yahoo.com
}


LIMA, D. D.; FREIRE, J. M. B.Professor de canto, preparador vocal, fonoaudiólogo, otorrinolaringologista: quais os limites e as interseções da relação entre os membros da equipe de atendimento ao cantor com base na nova pedagogia vocal? R. Científica UBM - Barra Mansa (RJ), ano XXX, v. 22, n. 43, 2 . Sem. 2020 p. 161-189. ISSN 1516-4071

\section{Resumo}

Este artigo discute a atuação do professor de canto em meio a outros profissionais que também atuam com a voz, como otorrinolaringologistas, fonoaudiólogos e preparadores vocais. Com base em uma revisão de literatura nas áreas de canto e fonoaudiologia, são definidas as especificidades das atuações de cada profissional de voz. A partir da compreensão das tendências pedagógicas na educação, são defendidas posições sobre o perfil do professor de canto em uma realidade em que ele não é mais o único detentor do conhecimento. Também é destacada a possibilidade de um trabalho integrado dos diversos profissionais de voz em atendimento ao cantor, mantidas suas especificidades e complementaridades.

Palavras-chave: Professor de canto. Profissionais da voz. Música. Fonoaudiologia. Voz cantada.

\section{Abstract}

This article discusses the role of the singing teacher among other professionals that also work with the voice, such as otorhinolaryngologists, speech language pathologists, and vocal coaches. The scope of practice of each voice-related professional is defined based on singing and speech language pathology literature. The role of the singing teacher - in a reality where they are not the only knowledge holders - is defended using the pedagogical tendencies in education as a starting point. The possibility of collaborative work by the many voicerelated professionals within their specific scopes of practice is also highlighted.

Key words: Singing teacher. Voice-related professionals, Music, Speech language pathology, Singing voice.

\section{Introdução}

Quando buscamos definir o que é voz, devemos nos atentar para o fato de que essa função orgânica é a integração de três aspectos: o anátomofisiológico, o físico-acústico e, também, o sociocomunicativo. Voz é som, com características específicas, que provém de um sistema biológico cuja condição afeta diretamente a qualidade do produto vocal final e que é utilizada para satisfazer necessidades que podem ser sociais, artísticas, emocionais, dentre 
LIMA, D. D.; FREIRE, J. M. B.Professor de canto, preparador vocal, fonoaudiólogo, otorrinolaringologista: quais os limites e as interseções da relação entre os membros da equipe de atendimento ao cantor com base na nova pedagogia vocal? R. Científica UBM - Barra Mansa (RJ), ano XXX, v. 22, n. 43, 2 . Sem. 2020 p. 161-189. ISSN 1516-4071

outras, e que estão sujeitas a variar de acordo com algumas características como idade, estilo de canto etc.

Trabalhar a voz de um cantor significa pedir permissão para acessar cada uma dessas dimensões constituintes da voz. Significa reconhecer o seu lugar de atuação e ter competência para agir em cada uma dessas dimensões.

Este artigo é parte de uma pesquisa de mestrado em andamento. Vamos apresentar aqui uma revisão de literatura nas áreas de educação, canto e fonoaudiologia, em que discutimos mudanças no perfil dos professores de canto, bem como trataremos da atuação dos diferentes profissionais que tratam da voz e que, muitas vezes, trabalham em conjunto com esses professores, ao lidar com cantores, sejam profissionais ou não.

\section{Fundamentação Teórica}

\section{AS TENDÊNCIAS PEDAGÓGICAS SEGUNDO LIBÂNEO}

Iniciaremos nossa discussão por um aspecto da atuação dos professores que enfatiza alguns dos pressupostos que estes trazem para seu trabalho docente: as tendências pedagógicas. De acordo com Libâneo (2001, p. 3), as práticas pedagógicas são condicionadas por fatores sociopolíticos, os quais dão origem a diferentes concepções de homem e de sociedade. Divide, então, as correntes pedagógicas em: Liberais e Progressistas, afirmando, no entanto, que as tendências não aparecem de forma pura e nem se excluem mutuamente, não sendo capazes, individualmente, de captar toda a riqueza de uma prática.

Para o referido autor, a pedagogia liberal não tem um caráter democrático avançado ou aberto, como seu nome pode sugerir. A doutrina liberal aparece como 
LIMA, D. D.; FREIRE, J. M. B.Professor de canto, preparador vocal, fonoaudiólogo, otorrinolaringologista: quais os limites e as interseções da relação entre os membros da equipe de atendimento ao cantor com base na nova pedagogia vocal? R. Científica UBM - Barra Mansa (RJ), ano XXX, v. 22, n. 43, 2 . Sem. 2020 p. 161-189. ISSN 1516-4071

[...] justificativa do sistema capitalista que, ao defender a predominância da liberdade e dos interesses individuais na sociedade, estabeleceu uma forma de organização social baseada na propriedade privada dos meios de produção, também denominada sociedade de classes. A pedagogia liberal, portanto, é uma manifestação própria desse tipo de sociedade. (LIBÂNEO, 2001, p. 5-6)

O autor diz ainda que, segundo essa visão pedagógica, os indivíduos devem

[...] adaptar-se aos valores e às normas vigentes na sociedade de classes, através do desenvolvimento da cultura individual. A ênfase no aspecto cultural esconde a realidade das diferenças de classes, pois, embora difunda a ideia de igualdade de oportunidades, não leva em conta a desigualdade de condições. (LIBÂNEO, 2001, p. 6)

Historicamente, de acordo com Libâneo (2001, p. 7), a educação liberal iniciou-se com a pedagogia tradicional, caracterizada pelo ensino humanístico no qual o aluno deve atingir sua realização pelo próprio esforço, em um contexto no qual os procedimentos e a interação com o professor não levam em consideração as realidades do discente. $\mathrm{O}$ professor, nesse modelo, impõe regras intelectualmente inquestionáveis.

Ainda segundo o referido autor, a vertente renovada dessa pedagogia acentua, igualmente, o sentido da cultura como desenvolvimento das aptidões individuais, entendendo a educação como um processo interno que deve ter como referência as necessidades e interesses individuais que permitem a adaptação ao meio, fazendo, assim, parte da própria experiência humana, e propondo um ensino centrado no aluno e no grupo.

A vertente renovada da pedagogia tradicional subdivide-se em: Progressivista, baseada na ideia do "aprender fazendo" (LIBÂNEO, 2001, p. 11), com ações constituídas a partir dos interesses e necessidades dos indivíduos, dando mais valor aos processos mentais e às habilidades cognitivas do que a 
LIMA, D. D.; FREIRE, J. M. B.Professor de canto, preparador vocal, fonoaudiólogo, otorrinolaringologista: quais os limites e as interseções da relação entre os membros da equipe de atendimento ao cantor com base na nova pedagogia vocal? R. Científica UBM - Barra Mansa (RJ), ano XXX, v. 22, n. 43, 2 . Sem. 2020 p. 161-189. ISSN 1516-4071

conteúdos organizados racionalmente; e em não diretiva, que foca nos aspectos psicológicos, devendo criar um clima favorável à uma mudança interna no indivíduo, e confere ao professor o papel de facilitador, que aceita a capacidade de autodesenvolvimento do aluno.

Há ainda, segundo Libâneo (2001), a vertente tecnicista da pedagogia liberal que acredita que a realidade contém suas próprias leis, que devem ser descobertas e aplicadas pelo homem, subordinando

[...] a educação à sociedade, tendo como função a preparação de "recursos humanos" (mão de obra para indústria). A sociedade industrial e tecnológica estabelece (cientificamente) as metas econômicas, sociais e políticas, a educação treina (também cientificamente) nos alunos os comportamentos de ajustamento a essas metas. (LIBÂNEO, 2001, p. 8)

Por outro lado, Libâneo (2001, p. 19) nos apresenta a pedagogia Progressista, que parte de uma análise crítica da realidade social, não tendo, assim, condições de se sustentar em sociedades capitalistas. A pedagogia progressista apresenta tendências:

A libertadora, mais conhecida como pedagogia de Paulo Freire, a libertária, que reúne os defensores da autogestão pedagógica; a críticosocial dos conteúdos que, diferentemente das anteriores, acentua a primazia dos conteúdos no seu confronto com as realidades sociais. As versões libertadora e libertária têm em comum o antiautoritarismo, a valorização da experiência vivida como base da relação educativa e a ideia de autogestão pedagógica. Em função disso, dão mais valor ao processo de aprendizagem grupal [...] do que aos conteúdos de ensino [...]; preferem as modalidades de educação popular "não-formal". A crítico-social [...] entende a escola como mediação entre o individual e o social, exercendo aí a articulação entre a transmissão dos conteúdos e a assimilação ativa por parte de um aluno concreto (inserido num contexto de relações sociais); dessa articulação resulta o saber criticamente re-elaborado. (LIBÂNEO, 2001, p. 20-25) 
LIMA, D. D.; FREIRE, J. M. B.Professor de canto, preparador vocal, fonoaudiólogo, otorrinolaringologista: quais os limites e as interseções da relação entre os membros da equipe de atendimento ao cantor com base na nova pedagogia vocal? R. Científica UBM - Barra Mansa (RJ), ano XXX, v. 22, n. 43, 2 . Sem. 2020 p. 161-189. ISSN 1516-4071

Paulo Freire (1996) também discutiu a atuação do professor e os saberes necessários à prática educativa. $\mathrm{O}$ autor tratou da relação entre professor e estudante, bem como dos papéis complementares de ambos no processo educativo.

Destacamos, inicialmente, um tema importante para o autor: a relação teoria e prática na educação. Freire (1996) valoriza a coerência entre o saber e a prática do docente, entendendo que a reflexão crítica sobre o próprio trabalho é uma condição necessária para uma educação transformadora e que esteja sempre em processo de atualização. "A reflexão crítica sobre a prática se torna uma exigência da relação Teoria/Prática sem a qual a teoria pode ir virando blábláblá e a prática, ativismo" (FREIRE, 1996, p. 24).

Outro ponto importante para ele é a compreensão do papel do estudante em sua própria formação, bem como a compreensão sobre o que é ensino, em sua visão:

É preciso, sobretudo, [...] que o formando, desde o princípio mesmo de sua experiência formadora, assumindo-se como sujeito também da produção do saber, se convença definitivamente que ensinar não é transferir conhecimento, mas criar as possibilidades para a sua produção ou a sua construção. (FREIRE, 1996, p. 24-25)

Ao enfatizar que o educando tem um papel ativo em sua formação, Freire ressalta uma forma de estar em sala de aula e enfatiza que o ensino não deve ser uma mera transmissão de conhecimento. $\mathrm{O}$ autor também destaca a importância do saber discente, alertando para que o docente trabalhe de maneira ética e acolha esse saber. Com isso, a educação tem seu caráter dialético reforçado, já que "toda prática educativa demanda a existência de sujeitos, um que, ensinando, aprende, outro que, aprendendo, ensina [...]" (FREIRE, 1996, p. 77).

Diante do que esses autores defendem, consideramos importante destacar o papel do professor como agente de transformação individual e social. 
LIMA, D. D.; FREIRE, J. M. B.Professor de canto, preparador vocal, fonoaudiólogo, otorrinolaringologista: quais os limites e as interseções da relação entre os membros da equipe de atendimento ao cantor com base na nova pedagogia vocal? R. Científica UBM - Barra Mansa (RJ), ano XXX, v. 22, n. 43, 2 . Sem. 2020 p. 161-189.

\section{ISSN 1516-4071}

Vivemos um momento em que a troca de saberes é uma grande possibilidade em sala de aula. Reconhecer a vantagem de uma relação professor-aluno menos hierarquizada é vital. Deve-se buscar a motivação do aluno e considerar a abertura para as tendências pedagógicas mais democráticas, considerando o repertório de experiências dos discentes, seus desejos e possibilidades.

Com a capacidade de entender o momento atual do aluno e um olhar descentralizado em relação a si mesmo, assim como com a competência técnica para guiá-lo para os resultados desejados, o professor será capaz de conduzir o processo de maneira clara, otimizada e proveitosa.

\section{A PEDAGOGIA DA VOZ CANTADA - UMA BREVE REVISÃO SOBRE A PEDAGOGIA TRADICIONAL E A CONTEMPORÂNEA}

$\mathrm{O}$ que difere a abordagem pedagógica atual do canto da abordagem tradicional? O ensino de canto popular, cada vez mais difundido, lida com um público formado por alunos que abarcam extrema diversidade: muitos estilos, vasta possibilidade de repertório e de características vocais, diferentes gostos e desejos.

De acordo com Alessandroni (2014), “a pedagogia da voz cantada é uma disciplina que se ocupa de estabelecer metodologias adequadas para o ensino do canto baseando-se em diferentes supostos teóricos básicos" (ALESSANDRONI, 2014, p. 23) ${ }^{1}$. Segundo o autor, todos os pedagogos vocais contemporâneos concordam com o fato de que há uma necessidade de se desenvolver uma pedagogia vocal diferente da tradicional, ainda que não haja um consenso sobre a melhor forma para desenvolver tal paradigma.

\footnotetext{
${ }^{1}$ La Pedagogía de la voz cantada entendida como la disciplina que se ocupa de establecer metodologias adecuadas para la enseñanza del canto basándose en diferentes supuestos teóricos básicos". Todas as traduções são dos presentes autores.
} 
LIMA, D. D.; FREIRE, J. M. B.Professor de canto, preparador vocal, fonoaudiólogo, otorrinolaringologista: quais os limites e as interseções da relação entre os membros da equipe de atendimento ao cantor com base na nova pedagogia vocal? R. Científica UBM - Barra Mansa (RJ), ano XXX, v. 22, n. 43, 2 . Sem. 2020 p. 161-189. ISSN 1516-4071

Em relação às perspectivas pedagógicas tradicionais,

[...] o ensino do canto se apoiou em experiências individuais dos professores de canto e nas recomendações herdadas de professores do passado. Assim, as noções pedagógicas relativas à voz foram sendo construídas mediante a recopilação de uma tradição basicamente oral, consistindo na transmissão de um saber fazer, instilado mediante a tradução de palavras referentes a sensações e propriocepções acústicas e fisiológicas. (MAULÈON, 2013, p. 78)²

Nesse caso, ainda de acordo com Maulèon (2013), há uma tendência de que cada professor desenvolva uma terminologia pessoal, que tende a ser modificada no futuro através das adaptações de seus próprios alunos, com base em sensações e percepções próprias. Segundo a autora, essa forma de pedagogia ainda prevalece e promove uma certa confusão em relação aos alcances terminológicos, podendo haver "um mesmo termo sendo empregado para dizer coisas diametralmente opostas" (MAULÈON, 2013, p. 79) ${ }^{3}$. Cita, ainda, uma dificuldade no entendimento do que é saudável ou não para a voz no que diz respeito ao ensino do canto. De acordo com a referida autora, alguns fatores inerentes à natureza do instrumento vocal acabam por justificar a maneira com a qual a pedagogia vocal se estabeleceu:

[...] (i) o intérprete não pode ver a fonte sonora (pregas vocais), a língua ou a forma do trato vocal; (ii) portanto, você deve descansar em suas próprias percepções e feedback auditivo para inferir o que está acontecendo em sua voz; (iii) além disso, grande parte do comportamento da voz não é diretamente acessível a processos conscientes (Welch e Sundberg, 2002); (iv) somente a partir do século

\footnotetext{
${ }^{2}$ Tradicionalmente, la enseñanza del canto se ha apoyado en las experiencias individuales de los maestros y en las recomendaciones heredadas de los enseñantes del pasado. De manera que las nociones pedagógicas relativas a la voz se fueron constituyendo mediante la recopilación de una tradición-básicamente oral-, consistente en la transmisión de un saber hacer, inculcado mediante la traducción a palabras de sensaciones y propiocepciones acústicas y fisiológicas".

3 "[...] que un mismo término sea empleado para decir cosas diametralmente opuestas".
} 
LIMA, D. D.; FREIRE, J. M. B.Professor de canto, preparador vocal, fonoaudiólogo, otorrinolaringologista: quais os limites e as interseções da relação entre os membros da equipe de atendimento ao cantor com base na nova pedagogia vocal? R. Científica UBM - Barra Mansa (RJ), ano XXX, v. 22, n. 43, 2 . Sem. 2020 p. 161-189. ISSN 1516-4071

XX é que a ciência produziu conhecimento confiável sobre o aparelho vocal e a função vocal (Maulèon, 2004). (MAULÈON, 2013, p. 79) ${ }^{4}$

Nesse padrão tradicional de ensino vocal há algumas características centrais, dentre as quais, segundo Alessandroni (2013), a necessidade de o aluno obter as mesmas competências de seu professor, sem questionamentos; a observação direta, através da qual o professor mostra suas habilidades esperando que o aluno faça igual sem nenhuma explicação; a ideia de que para ser cantor é necessário talento para reproduzir com habilidade o que o professor determinar; o foco absoluto no som produzido, negando as outras dimensões do processo vocal, como a corporal e a psicológica; o fato de os professores serem reconhecidos por sua trajetória artística e não por sua formação pedagógicometodológica; a transmissão oral de um saber fazer entre o professor de canto e o aluno, que pode vir a ser um futuro professor, tendendo a reproduzir esse padrão de ensino.

De acordo com Alessandroni (2014),

\begin{abstract}
A Pedagogia Vocal Contemporânea surge entre as décadas de 1950 e 1970 e se define como um modelo ou paradigma pedagógico cientificamente informado (Murry, 1969; Rosewall, 1961; Sundberg, 1987; Vennard, 1968). Os defensores deste paradigma argumentam que só é possível ensinar a cantar a partir de conhecimentos empiricamente validados. Desta maneira direcionam uma forte crítica aos pedagogos tradicionais, que, por não terem disponíveis conhecimentos estes tipos de conhecimento, basearam sua prática pedagógica na imitação, observação direta e utilização de um vocabulário subjetivo, que usualmente adotava a forma de expressões metafóricas (Hemsy de Gainza, 2002; Lavignac, 1950). A carência de evidência científica também determinou que os docentes focassem no som resultante (e não nas relações desse som com os mecanismos que permitem sua
\end{abstract}

\footnotetext{
4 "(i) el ejecutante no puede ver la fuente sonora (pliegues vocales), la lengua o la forma del tracto vocal; (ii) por lo tanto, tiene que descansar en sus propiocepciones y en el feedback auditivo para inferir qué esta ocurriendo en su voz; (iii) además, gran parte del comportamiento de la voz no es directamente accesible a los procesos concientes (Welch \& Sundberg, 2002); (iv) no fue sino hasta el siglo XX que la ciencia produjo conocimiento confiable sobre el aparato fonador y la función vocal".
} 
LIMA, D. D.; FREIRE, J. M. B.Professor de canto, preparador vocal, fonoaudiólogo, otorrinolaringologista: quais os limites e as interseções da relação entre os membros da equipe de atendimento ao cantor com base na nova pedagogia vocal? R. Científica UBM - Barra Mansa (RJ), ano XXX, v. 22, n. 43, 2 . Sem. 2020 p. 161-189. ISSN 1516-4071

produção) para avaliar o estado real de desenvolvimento do aluno. (ALESSANDRONI, 2014, p. 24) 5

A Pedagogia Vocal Contemporânea sofreu influência direta dos debates dicotômicos relativos ao binômio estrutura versus função, segundo Alessandroni (2014). A partir da segunda metade do século XX, as explicações sobre o fenômeno vocal envolveram conhecimentos provenientes fundamentalmente da Física, da Anatomia e da Fisiologia, sendo que a fisiologia era vista como subsidiária da anatomia até a metade do século XIX, havendo subordinação da função à estrutura. (ALESSANDRONI, 2014, p. 25).

O autor cita Danziger (1990):

O corpo era uma hierarquia estática de órgãos, cada um com sua função característica. Assim, questões sobre a função fisiológica só poderiam surgir depois que as estruturas, às quais as funções pertenciam, fossem anatomicamente estabelecidas. A unidade de pesquisa era o elemento anatômico visível e o método preferido era a dissecção. (DANZIGER, 1990, p. 25 apud ALESSANDRONI, 2014, p. 25) ${ }^{6}$

Assim, ainda de acordo com Alessandroni (2014), novos meios de observação das estruturas anatômicas surgiram, trazendo evolução para os diagnósticos, pois permitiam avaliação dinâmica dos tecidos.

\footnotetext{
${ }^{5}$ La Pedagogía Vocal Contemporánea surge entre los años 1950 y 1970 y se define como un modelo o paradigma pedagógico cientificamente informado (Murry, 1969; Rosewall, 1961; Sundberg, 1987; Vennard, 1968). Los defensores de este paradigma argumentan que sólo es posible enseñar a cantar a partir de conocimientos empíricamente validados. D e esta manera, direccionan una fuerte crítica a los pedagogos tradicionales que por no tener conocimientos de este tipo a disponibilidad, fundaron su práctica pedagógica en la imitación, la observación directa y la utilización de un vocabulário subjetivo que usualmente adoptaba la forma de expresiones metafóricas (Hemsy de Gainza, 2002; Lavignac, 1950). La carencia de evidencia científica también determino que los docentes se centraran en el sonido resultante (y no en las relaciones de ese sonido con los mecanismos que permiten su producción) para evaluar el estado real de desarrollo del alumno".

${ }^{6}$ El cuerpo era una jerarquía estática de órganos, cada uno con su función característica. Así, las cuestiones sobre la función fisiológica sólo podían surgir después de que las estructuras, a las cuales pertenecían las funciones, habían sido establecidas anatómicamente. La unidad de investigación era el elemento anatómico visible, y el método preferido era la disección" (grifo de Alessandroni).
} 
LIMA, D. D.; FREIRE, J. M. B.Professor de canto, preparador vocal, fonoaudiólogo, otorrinolaringologista: quais os limites e as interseções da relação entre os membros da equipe de atendimento ao cantor com base na nova pedagogia vocal? R. Científica UBM - Barra Mansa (RJ), ano XXX, v. 22, n. 43, 2 . Sem. 2020 p. 161-189.

ISSN 1516-4071

Otorrinolaringologistas e professores de canto propuseram como base $\mathrm{o}$ conhecimento anatômico da voz cantada, o que permitiria aos professores um ensino melhor. Essa é uma visão com foco na estrutura, uma posição chamada anatomista, que acredita que o canto é

[...] o resultado sonoro de uma macroestrutura conformada por diferentes estruturas anatômicas. [...] Outra consequência derivada desta posição é a crença de que as modificações sobre alguma estrutura anatômica são acessíveis para o cantor, e podem modificar o som resultante ou resolver problemas específicos (através de uma alteração na função específica desta estrutura). [...] Uma posição extremista em relação a esse paradigma anatomista resulta em métodos de ensino da voz cantada que dispensam o formato clássico de aula de música em que há uma interação linguística com o professor e propõe programas de treinamento assistido por software (Callaghan, Thorpe Doorn, 2004; Thorpe; Callaghan; Wilson; van Doorn; Cane; Jonathon, 2009). Essa modalidade promete obter resultados concretos a partir da observação na tela do computador dos gráficos acústicos (oscilogramas, espectrogramas, entre outros) correspondentes ao som vocal em tempo real. Assim, e com base em instruções curtas e precisas dos professores de canto (como "abaixe a língua" ou "adicione mais energia ao terceiro formante"), o aluno deve entender o que está vendo na tela como feedback visual imediato de sua produção vocal e corrigir as deficiências técnicas que ele exibe naquele momento. (ALESSANDRONI, 2014, p. 25-26) ${ }^{7}$

\section{Ainda segundo Alessandroni (2014),}

\footnotetext{
7 "[...] resultado sonoro de una determinada macroestructura conformada por diferentes estructuras anatómicas. [...] Outra consecuencia que se deriva de esta posición, es la creencia de que las modificaciones sobre alguna estructura anatómica son accesibles para el cantante, y pueden modificar el sonido resultante o resolver problemas específicos (a través de una alteración en la función específica de esa estructura). [...] Una posición extremista respecto de este paradigma anatomista resulta en métodos de la enseñanza del canto que prescinden del formato clásico de clase de canto en el cual se da una interacción lingüística com el docente y proponen programas de entrenamiento asistido mediante un software informático (Callaghan, Thorpe, y Doorn, 2004; Thorpe, Callaghan, Wilson, van Doorn, y Cane, Jonathon, 2009). Esta modalidade promete la obtención de resultados concretos a partir de la observación en la pantalla de una computadora de los gráficos acústicos (osciligramas, espectrogramas, entre otros) correspondientes al sonido vocal em tiempo real. Así, y a partir de instrucciones cortas y precisas por parte de los maestros de canto (como por ejemplo, 'bajá la lengua' o 'añadímás energía al tercer formante'), el alumno debería comprender lo que está viendo en la pantalla como feedback visual imediato de su producción vocal y corregir las falencias técnicas que exhiba en dicho momento".
} 
LIMA, D. D.; FREIRE, J. M. B.Professor de canto, preparador vocal, fonoaudiólogo, otorrinolaringologista: quais os limites e as interseções da relação entre os membros da equipe de atendimento ao cantor com base na nova pedagogia vocal? R. Científica UBM - Barra Mansa (RJ), ano XXX, v. 22, n. 43, 2 . Sem. 2020 p. 161-189.

ISSN 1516-4071

[...] no final da primeira metade do século XIX, a Fisiologia assumiu uma independência em relação à Anatomia. As funções não eram mais vistas como propriedades de unidades anatômicas visíveis, mas como objetos abstratos de pesquisa que também poderiam envolver muitos órgãos como processos invisíveis. [...] O mesmo parece ter tomado lugar na Pedagogia Vocal [...] com alguns docentes adotando uma visão ou posição funcional, privilegiando, assim, a função da fonação e tomando-a como uma unidade para a investigação. Os métodos de treinamento proprioceptivo parecem operar nessa direção, promovendo níveis mais altos de desenvolvimento da percepção do próprio corpo para conseguir modificações no nível funcional (Blades-Zeller, 2002; Fort Vanmeerhaeghe et al., 2009; Heirich, 20 11; Kind, 2011). Por exemplo, uma propriocepção mais aguda de diferentes áreas do corpo poderia permitir configurações posturais resultantes ideais para o canto, entendendo por ideais a uma postura que nos é funcional para a vida que levamos. (ALESSANDRONI, 2014, p. 26-27) ${ }^{8}$

Com foco no treinamento vocal, a posição fisiologista se distingue da anatomista. Compreende-se, assim, que não existe uma formação natural de um cantor, mas, sim,

[...] o treinamento do esquema corporal-vocal de uma maneira diferente daquela que utilizamos para a fala, com as estruturas envolvidas na produção do som organizadas segundo um padrão mais eficiente, alcançando o maior grau possível de diferenciação funcional. (ALESSANDRONI, 2014, p. 28) ${ }^{9}$

\footnotetext{
8 "[...] Hacia el final de la primera mitad del siglo XIX, la Fisiología logro independencia respecto de la Anatomía. Las funciones no se vieron más como propiedades de unidades anatómicas visibles, sino como objetos abstractos de investigación que podían involucrar muchos órganos así como procesos invisibles. E I mismo recorrido parece haber tenido lugar en Pedagogía Vocal. [...] algunos docentes adoptaron una mirada o posición funcional, privilegiando así la función de la fonación, y tomándola como unidad para la investigación. Los métodos de entrenamiento propioceptivo parecen funcionar en esta dirección, promoviendo mayores niveles de desarrollo de la percepción del propio cuerpo para lograr modificaciones en el nivel funcional (Blades-Zeller, 2002; Fort Vanmeerhaeghe et al., 2009; Heirich, 20 11; Kind, 2011). Por ejemplo, una propiocepción más aguda de diferentes zonas del cuerpo podría habilitar configuraciones posturales resultantes óptimas, entendiendo por óptima a una postura que nos es funcional para la vida que llevamos".

9 "[...] el entrenamiento de un esquema corporalvocal diferente del que utilizamos para el habla, en el cual las estructuras intervinientes en la producción del sonido se ensamblan según los patrones más eficientes para cantar o, lo que es lo mismo, alcanzan el mayor grado posible de diferenciación functional".
} 
LIMA, D. D.; FREIRE, J. M. B.Professor de canto, preparador vocal, fonoaudiólogo, otorrinolaringologista: quais os limites e as interseções da relação entre os membros da equipe de atendimento ao cantor com base na nova pedagogia vocal? R. Científica UBM - Barra Mansa (RJ), ano XXX, v. 22, n. 43, 2 . Sem. 2020 p. 161-189. ISSN 1516-4071

Segundo Miller (2011), no passado, a Fisiologia e a função vocal eram estudadas na Medicina, não pelos professores de canto, por não serem cientistas. No entanto, para ele, qualquer pessoa que estude a literatura histórica da pedagogia vocal poderá conferir a presença da visão científica da época relacionada à técnica vocal. Garcia, Vennard, e tantos outros grandes nomes da pedagogia vocal, são citados como pedagogos preocupados com os aspectos fisiológicos do canto (MILLER, 2011, p. 222). O autor ressalta, também, cientistas mais atuais que direcionam seus interesses para a voz cantada, como Titze e Sundberg, assim como um grande número de profissionais da área médica que se atêm à arte da voz cantada, trabalhando de perto com a comunidade de voz profissional, e conclui que "[...] a falta de informação a respeito dos aspectos fisiológicos do canto ainda é a marca registrada de um ensino ultrapassado"10 e que "o professor de canto deve conhecer a respeito da literatura de função vocal e da acústica da voz cantada assim como o médico precisa saber sobre diagnósticos e tratamento" (MILLER, 2011, p. 222; 223) ${ }^{11}$.

Cabe ressaltar que a formação tradicional possui seus próprios métodos e não pode ser considerada falida e ser descartada sumariamente por conta da existência de uma nova modalidade.

Se fizermos um retorno ao passado, vamos verificar a existência de inúmeros excelentes cantores treinados sob tal vertente. A atualização e a mudança de métodos e filosofias de ensino não pressupõem que todos os conhecimentos e modalidades anteriores sejam desqualificados. Percebemos muitas vantagens na maneira contemporânea de ensino, principalmente no que

\footnotetext{
10 "[...] avoidance of information regarding the physical aspect of singing is still the hallmark of some outmoded teaching".

11 "The teacher of singing needs to know the literature on vocal function and on the acoustics of the singing voice just as assuredly as the medical doctor needs to know the literature of diagnosis and treatment".
} 
LIMA, D. D.; FREIRE, J. M. B.Professor de canto, preparador vocal, fonoaudiólogo, otorrinolaringologista: quais os limites e as interseções da relação entre os membros da equipe de atendimento ao cantor com base na nova pedagogia vocal? R. Científica UBM - Barra Mansa (RJ), ano XXX, v. 22, n. 43, 2 . Sem. 2020 p. 161-189. ISSN 1516-4071

diz respeito ao olhar atencioso para o aluno e suas necessidades (o que não quer dizer que isso não acontecido no passado, apesar de não ser a tônica do trabalho descrito pela literatura existente); um olhar que torna possível ao professor capacitado e disposto a adequação das técnicas ao momento de cada um, dando margem a uma interação efetiva com o discente e a partir dele, gerando um ambiente participativo e integrado, o que tende a ser mais eficaz como processo educativo. Vale também dizer que, diante da grande diversidade artística do momento atual, essa visão é necessária para aqueles que tiverem o desejo de participar da formação profissional e artística de todos, sem distinção ou preconceitos quanto a qualquer tipo de manifestação vocal (desde que sob os preceitos de uma função vocal saudável) ou quanto a qualquer estilo musical.

Em relação à questão do conhecimento de Anatomia e Fisiologia por parte dos professores de canto, acreditamos ser uma necessidade e sabemos que os currículos da grande maioria das universidades já estão atualizados, com essas disciplinas incorporadas no conteúdo programático dos cursos de canto.

O que se pretende com esse conhecimento não é capacitar os professores para agirem como terapeutas em casos de alterações vocais, mas, sim, capacitálos para que possam direcionar seu processo de ensino-aprendizagem de maneira saudável, com a competência de guiar seus alunos por descobertas artísticas de forma segura e com a propriedade de quem conhece o instrumento que executa mesmo não estando à mostra. Dessa forma, é capaz de correlacionar timbres, nuances e ajustes aos processos orgânicos a eles referentes, o que gera intimidade com o instrumento vocal, característica que pode ser muito útil na retenção de padrões desenvolvidos para posterior utilização em outras performances e estudos. Conhecer. Sentir. Produzir. Reter. Criar padrões. Ações que ocorrem constantemente nas aulas de canto, e que são extremamente facilitadoras para a evolução artística e técnica do cantor. A ideia não é engessar 
LIMA, D. D.; FREIRE, J. M. B.Professor de canto, preparador vocal, fonoaudiólogo, otorrinolaringologista: quais os limites e as interseções da relação entre os membros da equipe de atendimento ao cantor com base na nova pedagogia vocal? R. Científica UBM - Barra Mansa (RJ), ano XXX, v. 22, n. 43, 2 . Sem. 2020 p. 161-189. ISSN 1516-4071

a arte, mas, sim, dar mais segurança para que ela ocorra livre, bem guiada e de forma saudável e longeva.

\section{A EQUIPE DE TREINAMENTO E ATENDIMENTO AO CANTOR - QUEM É QUEM E QUANDO/COMO CADA PROFISSIONAL DEVE ATUAR}

Segundo o otorrinolaringologista Brewer (1994), quando dizemos "voz", nos referimos ao campo da voz e devemos incluir todas as áreas que contribuem para esse estudo, apesar de ainda haver uma tendência à manutenção das barreiras clássicas que mantém assegurados os domínios de cada uma das áreas envolvidas. É consensual, porém, a necessidade de se "cultivar e alcançar um respeito em relação à contribuição de cada um áreas para um entendimento mais novo e mais integrado da voz humana" (BREWER, 1994, p. 360)..$^{12}$

Diante desse cenário, portanto, algumas dúvidas vêm à tona: como estabelecer uma linguagem unificada para o entendimento entre todos os profissionais envolvidos na equipe de atendimento e treinamento ao cantor? Os professores de canto precisam de um conhecimento anátomo-fisiológico e técnico sobre voz ou podem ser apenas cantores bons com carreiras brilhantes que decidem dar aulas? O que, de fato, um professor de canto precisa conhecer para realizar um bom trabalho? É necessário que o fonoaudiólogo seja especialista em voz para atuar com cantores? Quais os limites da atuação do fonoaudiólogo, especialista em voz, em relação ao atendimento a cantores? Quem é quem dentro de uma equipe multidisciplinar de treinamento e atendimento ao cantor?

\footnotetext{
12 "[...] to cultivate and achieve new respect for each other's contributions to a newer and more integrated understanding of the human voice".
} 
LIMA, D. D.; FREIRE, J. M. B.Professor de canto, preparador vocal, fonoaudiólogo, otorrinolaringologista: quais os limites e as interseções da relação entre os membros da equipe de atendimento ao cantor com base na nova pedagogia vocal? R. Científica UBM - Barra Mansa (RJ), ano XXX, v. 22, n. 43, 2 . Sem. 2020 p. 161-189. ISSN 1516-4071

\title{
CONTRIBUIÇÕES DA MEDICINA PARA O AVANÇO DO ATENDIMENTO
}

\section{AOS CANTORES}

Com o avanço da Medicina e das possibilidades diagnósticas nas últimas décadas, a visualização da laringe ficou mais acessível, sendo possível, inclusive, a observação do órgão em ação fonatória (o que é importantíssimo para a avaliação da função vocal, permitindo a professores de canto e fonoaudiólogos uma condição bastante assertiva para o direcionamento de seus fazeres). Novas técnicas cirúrgicas e novas perspectivas em relação a questões bastante comuns, como os microtraumas por abuso vocal, possibilitaram um aumento da assertividade nas práticas clínicas da voz.

De acordo com Brewer,

\begin{abstract}
Muito se aprendeu sobre a voz com as ciências médicas clássicas como anatomia, histologia, fisiologia, patologia e farmacologia. Como cada um desses campos se expandiu e se atualizou, novas tecnologias em pesquisa sobre voz foram adquiridas ao serem aplicadas, em uma variedade de combinações, no estudo do trato vocal. (BREWER, 1994, p. 360) ${ }^{13}$
\end{abstract}

Além disso, Brewer (1994) cita também a importância do avanço da Farmacologia, no que diz respeito ao compartilhamento de informações importantes e no conhecimentos de prejuízos que alguns medicamentos podem causar à voz, assim como a utilização de substâncias que ajudam o trabalho de reabilitação vocal, como no caso da toxina botulínica em disfonias

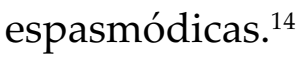

\footnotetext{
13 "Much has been learned about the voice from such classic medical sciences as anatomy, histology, physiology, pathology, and pharmacology. As each of these fields has expanded and been updated, new technologies in voice research have been acquired by applying them, in a variety of combinations, to the study of the vocal tract."

14 "Disfonia Espasmódica - Distúrbio pouco estudado, caracterizado por fonação intermitente com uma produção tensa-estrangulada" (TIZTE, 2013, p. 420).
} 
LIMA, D. D.; FREIRE, J. M. B.Professor de canto, preparador vocal, fonoaudiólogo, otorrinolaringologista: quais os limites e as interseções da relação entre os membros da equipe de atendimento ao cantor com base na nova pedagogia vocal? R. Científica UBM - Barra Mansa (RJ), ano XXX, v. 22, n. 43, 2 . Sem. 2020 p. 161-189.

\section{ISSN 1516-4071}

Essa seria, assim, uma parte das muitas contribuições que a área médica proporcionou ao estudo do fenômeno vocal, fornecendo a toda a equipe ferramentas para uma nova forma de observação e de cuidados com os profissionais da voz de uma maneira geral, incluindo os cantores, nosso objeto de pesquisa nesse caso específico.

\section{A IMPORTÂNCIA DA CIÊNCIA VOCAL NO PANORAMA DA EQUIPE DE ATENDIMENTO AO CANTOR}

Segundo Gill e Herbst (2016), um dos membros do painel da 10르 PVOC cita a existência do que diz ser "uma epidemia no mundo da voz: cantores aposentados tornando-se professores" (GILL; HERBST, 2016, p. 169) ${ }^{15}$. Para os autores, uma carreira de sucesso como cantor confere ao mesmo um grande autoconhecimento sobre a própria voz e provavelmente um bom conhecimento musical, mas questiona o fato de que esses quesitos não são suficientes para a docência, pois a pedagogia não se desenvolve somente através de uma subjetividade em relação à questão da percepção da própria função vocal.

Para os membros do painel, existe a necessidade de uma compreensão de que as variantes anatômicas individuais resultam em comportamentos vocais distintos e que, por conta disso, não deve haver um raciocínio de unificar as manifestações vocais, além de defenderem a necessidade do ensino de uma técnica vocal que deve ser "ajustada e otimizada para cada indivíduo" (GILL; HERBST, 2016, p. 169196. Citam, ainda, que há diversos níveis de diversidade que

\footnotetext{
15 "[...] an epidemic in the voice world: retired singers becoming teachers".

16 "[...] to be adjusted and optimized for each individual".

"Hipofaringe também denominada laringofaringe, é a porção mais inferior da faringe, que vai da orofaringe até a parte superior do esôfago" (HUNGRIA, 1995, p. 121).
} 
LIMA, D. D.; FREIRE, J. M. B.Professor de canto, preparador vocal, fonoaudiólogo, otorrinolaringologista: quais os limites e as interseções da relação entre os membros da equipe de atendimento ao cantor com base na nova pedagogia vocal? R. Científica UBM - Barra Mansa (RJ), ano XXX, v. 22, n. 43, 2 . Sem. 2020 p. 161-189. ISSN 1516-4071

devem ser considerados, dentre eles, o sexo, as classificações vocais, as variações anatômicas sutis - tais como diferenças entre a anatomia da hipofaringe ${ }^{17}$, diferentes velocidades das ondas mucosas, variações na geometria das pregas vocais e do canal da glote ${ }^{18}$ - , que, segundo eles deveriam ser mais conhecidas e estudadas, pois resultam em modificações no resultado acústico da voz. Assim, segundo eles, o pedagogo (ou professor de canto) deve tentar correlacionar o ensino da técnica vocal com as necessidades fisiológicas de cada aluno.

Segundo Gill e Herbst (2016), inspirados no pensamento de Haupt (2010), definem-se três áreas de responsabilidades para o treinamento vocal. São elas: a construção da voz, na qual questões fisiológicas do canto são consideradas, incluindo as habilidades musicais e a coordenação vocal; o treinamento em si, no qual todas as habilidades de performance são consideradas, incluindo até presença de palco e ímpeto dramático e a reabilitação da voz cantada.

Essas três áreas de responsabilidade representam papéis distintos na pedagogia da voz, e os indivíduos não são necessariamente limitados a um papel exclusivo. Dado adequado conhecimento e experiência, uma pessoa poderia de fato adotar papéis diferentes, mesmo durante o curso de uma única sessão de trabalho com um cantor, quando apropriado. (GILL; HERBST, 2016, p. 170) ${ }^{19}$

Para Colton (1994), cada disciplina traz para o estudo da voz seus próprio termos e jargões. Segundo ele, é necessário que os clínicos e professores entendam a natureza da investigação científica, assim como os cientistas devem

\footnotetext{
17 “Hipofaringe também denominada laringofaringe, é a porção mais inferior da faringe, que vai da orofaringe até a parte superior do esôfago" (HUNGRIA, 1995, p. 121).

18 "Glote - Espaço preenchido com ar entre as pregas vocais" (TITZE, 2013, p. 424).

19 "These three areas of responsibility represent distinct roles in voice pedagogy, and individuals are not necessarily limited to one exclusive role. Given proper knowledge and expertise, a person could indeed adopt different roles, even during the course of one work session with a singer when appropriate".
} 
LIMA, D. D.; FREIRE, J. M. B.Professor de canto, preparador vocal, fonoaudiólogo, otorrinolaringologista: quais os limites e as interseções da relação entre os membros da equipe de atendimento ao cantor com base na nova pedagogia vocal? R. Científica UBM - Barra Mansa (RJ), ano XXX, v. 22, n. 43, 2 . Sem. 2020 p. 161-189. ISSN 1516-4071

aprender a apreciar a arte de cantar e seus termos que, ainda que vagos em alguns momentos, figuram muito mais como inspiradores e motivacionais para os estudantes do que para explicar um conceito propriamente. Isso gera uma certa frustração nos cientistas, e até mesmo uma relação contraditória entre os profissionais envolvidos com o cantor. A boa notícia, de acordo com o autor, é que, ainda que não haja uma terminologia única, um senso comum e muitas vezes a discordância permaneça, percebe-se o início de um entendimento entre as partes da equipe, um lugar comum, onde uma área corrige a desinformação da outra e uma luz começa a surgir neste contexto.

Colton cita também o fato de que, anteriormente, não havia envolvimento direto de professores de canto, cantores e atores em pesquisas. Os que iniciaram suas pesquisas o fizeram por esforços próprios, como Jo Estill e Tom Cleveland, por exemplo. A população atual de cantores já está mais íntima da produção científica e não aceita mais as ideias simplesmente porque algum estudioso ou profissional escreveu em um livro. Eles querem razões, evidências que apoiem o conceito defendido.

De acordo com Colton (1994), as contribuições da ciência vocal são: o desenvolvimento de melhores métodos para a análise da função vocal, o desenvolvimento de melhores modelos para explicar e prever a função da prega vocal, e a aplicação dos princípios primordiais da ciência ao canto e à técnica de canto.

VOCAL COACHES OU TREINADORES VOCAIS, PROFESSORES DE CANTO

E FONOAUDIÓLOGOS - ANSEIOS E FUNÇÕES DESSES PROFISSIONAIS DENTRO DA EQUIPE DE ATENDIMENTO AO CANTOR 
LIMA, D. D.; FREIRE, J. M. B.Professor de canto, preparador vocal, fonoaudiólogo, otorrinolaringologista: quais os limites e as interseções da relação entre os membros da equipe de atendimento ao cantor com base na nova pedagogia vocal? R. Científica UBM - Barra Mansa (RJ), ano XXX, v. 22, n. 43, 2 . Sem. 2020 p. 161-189. ISSN 1516-4071

De acordo com Gill e Herbst (2016), a atuação do coach envolve a transferência e o estabelecimento de habilidades diretamente relacionadas ao palco ou estúdio, performance e expressividade artística, sendo, segundo os mesmos, a área que requer menos conhecimento de acústica e fisiologia da voz cantada e cujo trabalho deve ser realizado por alguém com muita experiência em performance e gravações, o que pode incluir não somente cantores bemsucedidos, mas outros membros da equipe como produtores e diretores. Citam, também, que um mesmo indivíduo pode acumular habilidades que lhe permitam ser coach e, paralelamente, professor de canto ou fonoaudiólogo, mas reforça o fato de serem áreas distintas e, por isso, requererem diferentes conhecimentos, assim como o fato de um vocal coach experiente poder correr o risco de se aventurar em uma área de construção vocal e vir a perceber que não possui ferramentas necessárias para tal finalidade.

Sugestões técnicas de alguém sem treinamento adequado em Anatomia, Fisiologia e Acústica da voz podem ter o potencial de frustrar e confundir um cantor, atrasar o processo de treinamento e, na pior das hipóteses, pode levar ao estabelecimento de hábitos ineficientes de canto e lesão vocal. Nesse contexto, coaches precisam ser cuidadosos com estímulos de cunho emocional, alguns das quais poderiam influenciar a função vocal de formas indesejadas, temporária ou cronicamente, neutralizando, assim, o trabalho realizado na construção da voz. (GILL; HERBST, 2016, p. 171) ${ }^{20}$

Para Rubin (1994), treinadores ou coaches, fonoaudiólogos e professores de canto são todos educadores vocais. De acordo com Raphael (1994), treinador

\footnotetext{
20 "Technical suggestions from someone without proper training in the anatomy, physiology, and acoustics of the voice may have the potential to frustrate and confuse a singer, slow down the process of training, and, as a worst-case scenario, might lead to the establishment of inefficient singing habits and voice injury. In this context, coaches might also be careful with emotional inputs, some of which could influence the vocal function in unwanted ways, either temporarily or chronically, thus counteracting the work done in voice building".
} 
LIMA, D. D.; FREIRE, J. M. B.Professor de canto, preparador vocal, fonoaudiólogo, otorrinolaringologista: quais os limites e as interseções da relação entre os membros da equipe de atendimento ao cantor com base na nova pedagogia vocal? R. Científica UBM - Barra Mansa (RJ), ano XXX, v. 22, n. 43, 2 . Sem. 2020 p. 161-189.

\title{
ISSN 1516-4071
}

vocal, os próprios estudos a respeito da Ciência da Voz lhe trouxeram como maior legado a visão sobre a ressonância vocal, passando, graças à reunião de vários profissionais em simpósios e com as trocas ocorridas nesses eventos, a compreender alguns conceitos com maior clareza em relação à função vocal.

\begin{abstract}
Comecei a relacionar as posições de língua e mandíbula e como elas se relacionam com o conceito do que passei a chamar de "alinhamento vocal interno" para a produção de um som saudável, bem projetado, flexível e responsivo. Dessa forma, penso que estou chegando próximo aos caminhos pelos quais professores de canto ajudam cantores experientes a melhorar o tom de suas vozes. (RAPHAEL, 1994, p. 366) 21
\end{abstract}

Ainda de acordo com Raphael (1994), deveria haver um vocabulário comum a todos que trabalham com voz, apesar de saber que essa é uma tarefa difícil. O autor diz ser muito importante que os termos técnicos tenham o significado conhecido por todos, e que essa situação beneficiaria os estudos de todos os envolvidos.

Para Miller (1994), professor de canto e pedagogo vocal, ao contrário do que geralmente se supõe, os professores de canto sempre se interessaram pelo funcionamento do instrumento vocal e cita como prova disso o fato de um professor de canto ter sido o primeiro a inventar o próprio espelho laríngeo, e não um médico. Diz também que, apesar de nem sempre ter havido muitas informações, os professores de canto usavam de todas as informações científicas disponíveis, e muitas vezes se viam excluídos do direito de colaborarem porque "lhes faltava uma linguagem precisa para expressar seu conhecimento empírico

\footnotetext{
21 "I have begun to address tongue and jaw positions as they relate to the concept of what I would call 'internal vocal alignment' for the production of healthy, projectible, flexible, responsive, and beautiful sound. In this respect I think that I am actually moving closer to the ways in which singing teachers help experienced vocalists to improve their vocal tone."
} 
LIMA, D. D.; FREIRE, J. M. B.Professor de canto, preparador vocal, fonoaudiólogo, otorrinolaringologista: quais os limites e as interseções da relação entre os membros da equipe de atendimento ao cantor com base na nova pedagogia vocal? R. Científica UBM - Barra Mansa (RJ), ano XXX, v. 22, n. 43, 2 . Sem. 2020 p. 161-189.

ISSN 1516-4071

sobre o próprio instrumento vocal" (MILLER, 1994, p. 367)22 . E Miller acrescenta

que isso ocorre

Em grande parte, porque a voz foi considerada por tanto tempo o instrumento 'oculto', mitologias sobre função vocal passaram a tipificar a linguagem da profissão de ensino de voz. [...] não existiam métodos de medir e comparar as muitas e conflituosas suposições sobre o canto artístico. Tudo o que podíamos fazer era levantar hipóteses; não conseguíamos verificar nossas convicções. (MILLER, 1994, p. 367)23

Ainda de acordo com Miller (1994), o professor de canto, assim como os

demais membros da equipe do cantor, deseja evitar o abuso vocal e completa dizendo que, se a técnica de canto não estiver de acordo com o equilíbrio das funções fisiológica e acústica, correrá o risco de haver o surgimento de problemas vocais. Entretanto,

Ainda existe uma minoria de professores de voz que tende a resistir à necessidade de informação científica sobre a produção de voz por medo de diminuir a questão artística do canto. Eles dizem: "Eu nunca falaria com um aluno sobre acústica ou fisiologia no canto"; ainda assim, cada vez que os professores de canto dizem ao aluno para soltar a mandíbula, para não deixar cair a mandíbula, puxar para dentro o abdômen ou empurrar para fora ou para baixo o abdômen, "coloque a nota", "apoie na respiração", "coloque o som na máscara" ou "apoie a nota", o que eles estão fazendo é lidar com fisiologia e acústica. $\mathrm{Na}$ medida em que a voz é um instrumento físico, é lógico que suas funções mecânicas não devem estar envoltas em mistério, mitologia ou linguagem imaginativa. (MILLER, 1994, p. 368) ${ }^{24}$

\footnotetext{
22 "They lacked a precise language by which to express their empirical knowledge about the vocal instrument itself".
}

23 "Largely because the voice for so long was considered the 'hidden' instrument, mythologies about vocal function came to typify the language of the voice teaching profession. [...] there did not exist methods of measuring and comparing the many conflicting assumptions about artistic singing. All we could do was hypothesize; we could not verify our convictions".

24 "There still exists a minority of voice teachers that tends to resist the need for scientific information about voice production out of fear it will diminish artistry. They say, 'I would never speak to a student about acoustics or physiology in singing'; yet, any time singing teachers tell a student to drop the jaw, not to drop the jaw, to pull inward on the abdomen, or to push outward or downward on the abdomen, to 'place the tone,' to 'sing on the breath,' to 'put the sound in the masque,' or to 'support the tone,' they are dealing in physiology and acoustics. Inasmuch as the voice is a physical instrument, it is logical that its mechanical functions should not be shrouded in mystery, mythology, or imaginative language". 
LIMA, D. D.; FREIRE, J. M. B.Professor de canto, preparador vocal, fonoaudiólogo, otorrinolaringologista: quais os limites e as interseções da relação entre os membros da equipe de atendimento ao cantor com base na nova pedagogia vocal? R. Científica UBM - Barra Mansa (RJ), ano XXX, v. 22, n. 43, 2 . Sem. 2020 p. 161-189. ISSN 1516-4071

Para Moore (1994), pioneiro na área da ciência vocal e da reabilitação, a Fonoaudiologia é uma jovem ciência se comparada às demais envolvidas nas artes e os fonoaudiólogos deveriam entender que não são os criadores de muitas das coisas que pensam que são. Para ele, existe algo muito importante a ser organizado: a distância entre aquilo que sabemos e a maneira como usamos esse conhecimento. Como fazemos com que nossos clientes entendam o que queremos dizer a eles?

\begin{abstract}
Parece-me que o professor ou clínico que está tentando transpor conhecimento para o comportamento tem o trabalho mais difícil em todo o nosso campo. É relativamente fácil separar amostras em laboratório, é relativamente fácil diagnosticar um problema, mas quando a questão é modificar os comportamentos de pessoas atingidas por distúrbios específicos, essa é para mim a tarefa mais difícil que temos. Tiro meu chapéu para os professores e médicos que trabalham dia após dia, individualmente e em pequenos grupos, tentando desenvolver lições motivacionais que guiam as pessoas a realmente progredirem. Felizmente, há uma grande promessa pela frente. Eu vejo em um futuro relativamente próximo, o desenvolvimento de materiais didáticos que vão muito além de onde estamos agora: materiais que ajudarão oradores e cantores a alcançarem suas capacidades máximas [...]. (MOORE, 1994, p. 373-374) ${ }^{25}$
\end{abstract}

De acordo com Gill e Herbst (2016), quando o assunto é a reabilitação vocal, é importante considerarmos o motivo do comprometimento vocal.

\footnotetext{
25 "It seems to me that the teacher or clinician who is trying to transpose knowledge to behavior has the hardest job in our whole field. It is relatively easy to pull specimens apart in the laboratory, it is relatively easy to diagnose a problem, but when it comes right down to transferring information about a disorder to what particular persons must do to modify their behaviors, this is to me the most difficult task we have. I take my hat off to the teachers and clinicians who are working day after day, one on one and in small groups, trying to develop motivational lessons that guide persons to actually make progress. Fortunately, there is great promise ahead. I see in the relatively near future the development of teaching aids that will go far beyond where we are now: aids that will help speakers and singers to reach their maximum capabilities".
} 
LIMA, D. D.; FREIRE, J. M. B.Professor de canto, preparador vocal, fonoaudiólogo, otorrinolaringologista: quais os limites e as interseções da relação entre os membros da equipe de atendimento ao cantor com base na nova pedagogia vocal? R. Científica UBM - Barra Mansa (RJ), ano XXX, v. 22, n. 43, 2 . Sem. 2020 p. 161-189. ISSN 1516-4071

Segundo os autores, os prejuízos podem ser em geral por uso impróprio da voz ou por distúrbios da voz que podem ter surgido independentemente de o paciente ser um cantor.

Ainda segundo Gill e Herbst (2016), os sintomas de ambas as categorias podem ser tratados por profissionais da área médica que não tenham nenhuma relação com a voz cantada. No entanto, quando as alterações são adquiridas durante o uso da voz cantada, é necessário que a equipe tenha treinamento em Fisiologia da voz cantada.

Nesse contexto, certos hábitos laríngeos indesejáveis podem interferir gravemente com os objetivos da construção da voz, e estes precisam ser abordados de forma terapêutica e em um contexto de reabilitação.

\section{Considerações Finais}

Neste artigo apresentamos questões relacionadas à atuação do professor de canto a partir de considerações sobre uma educação mais centrada no estudante. Apresentamos uma tendência mais recente do ensino de canto que busca uma fundamentação científica para a técnica vocal e como tem havido uma aproximação com profissionais da área da saúde que podem atuar conjuntamente no cuidado com o cantor.

Embora, como Miller (2011) disse, o ensino de canto tenha refletido, em cada época, o tipo de conhecimento científico disponível, essa busca por evidências que sustentem ou descartem práticas de treinamento vocal apresenta novas possibilidades, como a divulgação científica de forma mais disseminada, bem como o uso de ferramentas de busca na internet, além de outros meios digitais. Isso levou à proliferação de possibilidades de acesso à informação, sem que, necessariamente, seja uma informação realmente embasada. Cada vez mais existe a possibilidade de vender produtos e treinamentos que, nem sempre, são 
LIMA, D. D.; FREIRE, J. M. B.Professor de canto, preparador vocal, fonoaudiólogo, otorrinolaringologista: quais os limites e as interseções da relação entre os membros da equipe de atendimento ao cantor com base na nova pedagogia vocal? R. Científica UBM - Barra Mansa (RJ), ano XXX, v. 22, n. 43, 2 . Sem. 2020 p. 161-189. ISSN 1516-4071

ofertados por profissionais competentes e que podem não abranger um conhecimento que auxilie o cantor em seu percurso.

Diante de uma conduta baseada na nova pedagogia do canto, o professor será levado a reconhecer em seus alunos as individualidades que os caracterizam e que fazem deles artistas únicos e originais, entendendo o discente como agente do processo, ao invés de, como cita Maulèon (2013), apenas transmitir o seu saber fazer, como na pedagogia tradicional; ele irá, estrategicamente, facilitar o desenvolvimento do fazer do próprio aluno.

Esse estudante como elemento ativo no processo educacional, irá, como sugere Freire (1996), acolher o saber trazido pelo discente para as aulas, que serão transformadas em atividades dialéticas, em que ambos, professor e aluno ensinam e aprendem, reciprocamente.

Exercer uma pedagogia não centralizada no professor, aprendendo a ouvir e a entender o aluno, e ter em mãos ferramentas apropriadas para aplicar na condução de suas aulas pode fazer com que o trabalho seja cada vez mais efetivo e satisfatório. Saber dialogar também é uma habilidade necessária para um ensino mais individualizado. Essa relação da construção do que eu chamaria de persona vocal artística é um dos momentos que considero mais importantes e especiais da relação professor de canto-aluno. ${ }^{26} \mathrm{E}$ isso é de uma profundidade que nunca, jamais, deve ser desprezada.

Entendemos que, hoje em dia, o interesse pela saúde e por uma medicina preventiva tem ganhado espaço e que, nesse contexto, faz sentido que essa preocupação se estenda para a atividade do músico prático, incluindo o cantor. A troca realizada em ambientes multidisciplinares, em congressos e em publicações científicas, aproxima as diversas áreas do saber e propicia aos

\footnotetext{
${ }^{26}$ Daqui em diante, sempre que os verbos estiverem em primeira pessoa, referem-se à autora Danielle Lima.
} 
LIMA, D. D.; FREIRE, J. M. B.Professor de canto, preparador vocal, fonoaudiólogo, otorrinolaringologista: quais os limites e as interseções da relação entre os membros da equipe de atendimento ao cantor com base na nova pedagogia vocal? R. Científica UBM - Barra Mansa (RJ), ano XXX, v. 22, n. 43, 2 . Sem. 2020 p. 161-189. ISSN 1516-4071

profissionais uma visão mais integrada, fato que colabora para a eficiência e plenitude do trabalho realizado.

Ainda de acordo com uma atitude atual e integrada, o professor de canto utiliza-se dos conhecimentos das ciências médicas clássicas, como a anatomia e a fisiologia, nas quais deveria fundamentar sua técnica de canto, evitando, conforme citado por Miller (1994), os abusos vocais que podem gerar problemas.

Vale ressaltar que o fato de o professor de canto absorver conhecimentos anatomofisiológicos não faz dele um terapeuta, assim como o fato de um fonoaudiólogo, por exemplo, ter acesso ao estudo das vertentes artísticas do canto não faz dele um professor de canto. Cada profissional manterá sua área de atuação e deverá respeitar seus limites.

Atualmente podemos observar profissionais muito bem preparados em equipes de trabalho com cantores.

Laringologistas especialistas em cantores, extremamente bem equipados e qualificados, com tecnologia de última geração que permite uma avaliação precisa da anatomia do aparelho fonador, bem como de sua função; fonoaudiólogos, preferencialmente especialistas em voz, conhecedores de anatomia e fisiologia da voz e, bem orientados em relação às questões musicais, estilos de canto e suas necessidades tímbricas, talvez sejam os profissionais que atuarão com maior proximidade em relação aos professores de canto, ajudandoos a alcançar os padrões vocais/interpretativos desejados por seu cliente, sempre que não forem obtidos de uma forma natural ou quando algum desajuste ocorrer. Podem atuar, também, a título de prevenção, orientando e condicionando o cantor no intuito de minimizar os riscos de surgimento de uma lesão ou alteração vocal. Levar o cantor a atingir a eficiência vocal é o papel do fonoaudiólogo: a máxima capacidade de performance, com o mínimo desgaste possível, propondo intervenções individualizadas e apropriadas para cada necessidade específica. 
LIMA, D. D.; FREIRE, J. M. B.Professor de canto, preparador vocal, fonoaudiólogo, otorrinolaringologista: quais os limites e as interseções da relação entre os membros da equipe de atendimento ao cantor com base na nova pedagogia vocal? R. Científica UBM - Barra Mansa (RJ), ano XXX, v. 22, n. 43, 2 . Sem. 2020 p. 161-189. ISSN 1516-4071

Com relação à ciência da voz, esta deveria se aproximar das artes, preocupando-se com as necessidades dos professores e tentando trabalhar para supri-las. Essa deveria ser uma relação de mão dupla, de troca e apoio, e esse caminho vem sendo desenvolvido por muitos profissionais, o que nos deixa bastante otimistas em relação ao futuro.

O que falta, então, para que haja um alinhamento maior entre professores de canto e os demais profissionais das equipes de atendimento aos cantores? A meu ver, principalmente no que diz respeito ao canto popular (que é a minha realidade de atuação), falta um vocabulário comum a todos. Chegar a esse vocabulário comum é um processo que não nos parece muito simples, pois há diversidade e até mesmo divergência dentro de cada área envolvida. Nesse processo, tanto a área da saúde quanto a da música terão que se apropriar dos termos específicos uma da outra para que não seja um movimento forçado em que uma área se impõe à outra. Os maiores benefícios do trabalho multidisciplinar poderão ser atingidos com um diálogo em que não haja equívocos de entendimento quanto às necessidades do cantor.

Para finalizar, destacamos que uma importante forma de contato, aproximação e convergência entre as áreas pode ser a pesquisa sobre a voz cantada.

Constatamos que ainda há uma carência em pesquisas sobre esse tema no Brasil. A investigação científica pode fundamentar práticas utilizadas no ensino de canto ou até estimular a geração de novas. A pesquisa pode servir, também, para desmistificar certos temas ou evitar práticas que não estão realmente de acordo com os fundamentos científicos da voz, o que, no nosso entender, pode contribuir para que o diálogo entre a área de saúde e a da música seja reforçado. 
LIMA, D. D.; FREIRE, J. M. B.Professor de canto, preparador vocal, fonoaudiólogo, otorrinolaringologista: quais os limites e as interseções da relação entre os membros da equipe de atendimento ao cantor com base na nova pedagogia vocal? R. Científica UBM - Barra Mansa (RJ), ano XXX, v. 22, n. 43, 2 . Sem. 2020 p. 161-189. ISSN 1516-4071

\section{Referências}

ALESSANDRONI, N. Pedagogía Vocal comparada. Qué sabemos y qué no. Arte e Investigación, 9. La Plata: Facultad de Bellas Artes, UNLP, 2013.

ALESSANDRONI, N. Estructura y función en Pedagogía Vocal Contemporánea. Tensiones y debates actuales para la conformación del campo. Revista de Investigaciones en Técnica Vocal, Año 2, no2, p. 23-33. La PlataFacultad de Bellas Artes, UNLP, 2014.

BREWER, David W. The Laryngologist's Perspective. In: SCHERER, Ronald C. (Mod.; Ed.) et al. The integration of voice science, voice pathology, medicine, public speaking, acting, and singing. Journal of Voice, v. 8, n. 4 p. 359-374, 1994.

COLTON, Raymond. The Voice Scientist's Perspective. In: SCHERER, Ronald C. (Mod.; Ed.) et al. The integration of voice science, voice pathology, medicine, public speaking, acting, and singing. Journal of Voice, v. 8, n. 4 p. 359-374, 1994.

FREIRE, Paulo. Pedagogia da autonomia: saberes necessários à prática educativa. São Paulo: Paz e Terra, 1996

GILL, Brian P.; HERBST, Christian T. Voice pedagogy - what do we need?, Logopedics Phoniatrics Vocology, v. 41, n. 4, p. 168-173, 2016.

HUNGRIA, Helio. Otorrinolaringologi $a$. $^{\circ}$ edição. Rio de Janeiro: Guanabara Koogan, 1995.

LIBÂNEO, J. C. Democratização da escola pública: a pedagogia crítico-social dos conteúdos. 19ª ed. São Paulo: Loyola, 2001.

MAULÈON, C. Arte y Ciencia. Hacer y Pensar la Pedagogía Vocal. Revista de Investigaciones en Técnica Vocal, Año 1, n¹. La Plata: Facultad de Bellas Artes UNLP, 2013.

MILLER, Richard. The Perspective of the Singing Teacher and Voice Pedagogue. In: SCHERER, Ronald C. (Mod.; Ed.) et al. The integration of voice 
LIMA, D. D.; FREIRE, J. M. B.Professor de canto, preparador vocal, fonoaudiólogo, otorrinolaringologista: quais os limites e as interseções da relação entre os membros da equipe de atendimento ao cantor com base na nova pedagogia vocal? R. Científica UBM - Barra Mansa (RJ), ano XXX, v. 22, n. 43, 2 . Sem. 2020 p. 161-189. ISSN 1516-4071

science, voice pathology, medicine, public speaking, acting, and singing. Journal of Voice, v. 8, n. 4 p. 359-374, 1994.

MILLER, Richard. On the Art of Singing. New York: Oxford University Press, 2011. Kindle Edition.

MOORE, G. Paul. The Perspective of the Speech Pathologist and Voice Researcher. In: SCHERER, Ronald C. (Mod.; Ed.) et al. The integration of voice science, voice pathology, medicine, public speaking, acting, and singing. Journal of Voice, v. 8, n. 4 p. 359-374, 1994.

RAPHAEL, Bonnie N. The Voice Trainer's Perspective. In: SCHERER, Ronald C. (Mod.; Ed.) et al. The integration of voice science, voice pathology, medicine, public speaking, acting, and singing. Journal of Voice, v. 8, n. 4 p. 359-374, 1994.

RUBIN, Lucille S. The Voice Trainer's Perspective. In: SCHERER, Ronald C. (Mod.; Ed.) et al. The integration of voice science, voice pathology, medicine, public speaking, acting, and singing. Journal of Voice, v. 8, n. 4 p. 359-374, 1994.

SUNDBERG, Johan. Ciência da Voz: Fatos sobre a Voz na fala e no Canto. São Paulo: Editora da Universidade de São Paulo, 2015.

TITZE, Ingo. Princípios da produção vocal. Salt Lake City: National Center of Voice and Speech, 2013. 